\title{
Evaluating the Risk of Opioid Abuse in Chronic Pain Patients by Addiction Psychiatry Fellows in an Academic Pain Center
}

\author{
Alexandra M Lesenskyj, Arash Danesh, Sameer Jain, Christina R Maxwell, Charles Perkel and Ricardo A \\ Cruciani* \\ Department of Neurology, Drexel Neuroscience Institute, Drexel University College of Medicine, USA
}

Submission: November 21, 2016; Published: November 30, 2016

*Corresponding author: Ricardo A Cruciani, Department of Neurology, Drexel Neuroscience Institute, Drexel University College of Medicine, Philadelphia, Pennsylvania, USA, Tel: 215-762-7090; Email: Ricardo.Cruciani@drexelmed.edu

\begin{abstract}
Context: Assessing risk of abuse plays an important role in deciding to prescribe opioids for the management of chronic pain.

Objective: This study was designed to assess feasibility and effectiveness of opioid prescribing risk assessment by addiction psychiatry fellows during their rotation in a pain clinic in an academic center.
\end{abstract}

Methods: A total of 202 chronic pain patients were evaluated for opioid prescribing risk. Seven addiction psychiatry fellows evaluated opioid prescribing risk in chronic pain patients during their rotation in the pain clinic required as part of their training. One-time patient evaluations for opioid abuse risk were conducted in a once a week $1 / 2$ day clinic pain clinic. Patient demographics, diagnoses, treatment course, and recommendations were prospectively collected. The main outcome of this study was to determine the number of patients at a high-risk for opioid abuse who were identified as a result of this program.

Results: Abnormal toxicology results and high-risk for opioid prescribing was found in 128 patients. Of patients referred for consultation, only $2 \%$ were recommended for continued opioid therapy.

Conclusion: This feasibility study suggests that supervised addiction psychiatric fellows can conduct opioid prescribing risk assessment effectively. This additional level of assessment was requested by less experienced practitioners, like fellows, while seasoned attending physicians were less inclined to request assistance. Larger multicenter studies are needed to confirm these findings.

Keywords: Chronic pain; Opioid management; Addiction

\section{Introduction}

Historically, opioids have played a crucial role in the management of pain [1-3]. However, long-term opioid therapy is now controversial due to reports of increases in accidental deaths associated with prescription opioids [4]. These reports have shifted the clinical focus from restricting access to medications to risk assessment and harm reduction [5,6]. Aberrant drug related behavior (ADRB) is a term used to describe patient deviation from safe utilization of prescription opioids and serves as an indicator of risk. ADRB in pain clinics varies among studies and ranges from $1 \%$ to $85 \%$ [7-11]. Some tools that assess prescription opioid-related risk include the Opioid Compliance Checklist, the ORBIT (opioid related behavior in treatment) scale, the Current Opioid Misuse Measure (COMM), and the prescription drug use questionnaire (PDUQ) [12-15]. Additionally, Wiedemer and colleagues proposed a structured refill clinic model to better assess risk and mitigate harm [16].

In most places, however, the implementation of a refill clinic like this would require additional resources; feasibility needs to be addressed. In many occasions, determination of risk in initiation or continuation of opioid therapy can be challenging. For this reason, practitioners may need assistance from drug addiction psychiatrists. Unfortunately urgent appointments for these types of assessments are very difficult to arrange impacting assessment and management $[1,6,16]$. To address these concerns we have developed a system suitable for Academic Centers that takes advantage of existing resources. In the system that we are 
proposing addiction psychiatry fellows assist pain practitioners during their rotation in the pain clinic. This collaboration allows for assessment and disposition of patients at risk of opioid misuse in the form of ADRB (Table 1).

Table 1: Demographic information regarding patients evaluated by addiction psychiatry fellows in a pain clinic $(n=202)$.

\begin{tabular}{|c|c|}
\hline Demographics & \\
\hline Female & 80 \\
\hline Male & 122 \\
\hline Average Age (mean years \pm SD) & $52 \pm 10.86$ \\
\hline Range (years) & $26-72$ \\
\hline
\end{tabular}

\section{Methods}

Addiction psychiatry fellows at an academic medical center rotate for 4 months in the Pain Clinic of the same Institution as part of their training. Pain practitioners (Attending Physicians, Pain Fellows and Nurse Practitioners), were advised that they could refer patients to the addiction psychiatry fellows during their rotation, to assist with the assessment of risk associated to opioid prescribing. Fellows had a weekly $1 / 2$ a day session where they performed an on-site one time evaluation. The Chief of the Pain Division and the Director of the Addiction Psychiatry Fellowship supervised the evaluations.

In this prospective study we examined,

A. the nature of the consultations requested by pain practitioners (attending physicians, nurse practitioners and fellows),

B. the characteristics of the patients referred for the assessment,

C. the referrals by the addiction psychiatry fellows for those patients identified as not suitable for opioid prescribing,

D. the referrals of those patients that could continue opioid therapy but were considered to be at risk,

E. The usefulness of the experience for the addiction psychiatry fellows.

\section{Results}

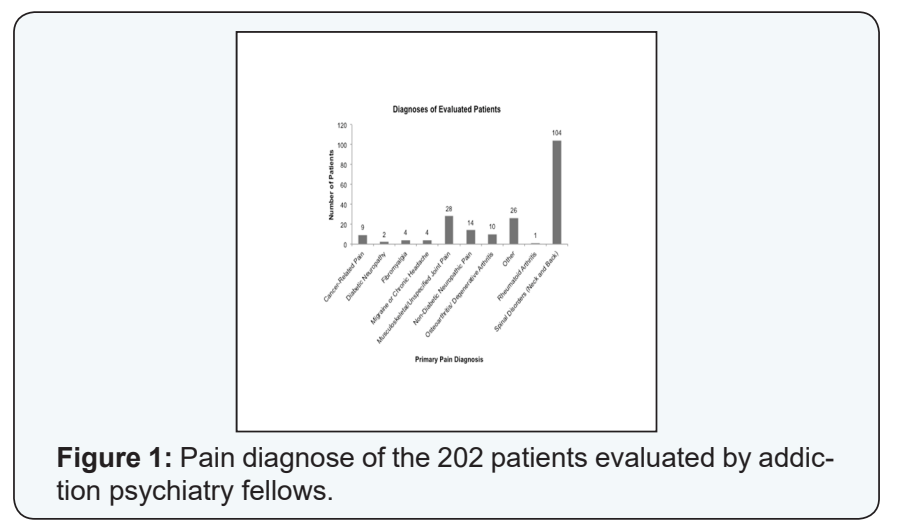

A total of 202 patients were evaluated, 80 of which were female. Ages ranged from 26 to 72 years with a mean of 52 years. Diagnoses were provided by the referring practitioners (Figure 1). Primary pain diagnoses were grouped as follows: spinal disorders (51\%), musculoskeletal/unspecified joint pain (14\%), other (13\%), non-diabetic neuropathic pain (7\%), osteoarthritis/ degenerative arthritis (5\%), cancer-related pain (4\%), fibromyalgia (2\%), migraine or chronic headache $(2 \%)$, diabetic neuropathy (1\%), rheumatoid arthritis (>1\%). Twenty-seven patients reported more than one pain diagnosis, a majority of which had a combination of spinal disorders and musculoskeletal pain. Pain fellows and nurse practitioners requested $95 \%$ of the consultations. The most frequent reason to request evaluation was assessment for risk of continuation of opioid therapy (63\%).

One hundred and twenty eight patients (63\%) had abnormal toxicology results, all of who were stratified as high risk. Seven of these patients (5\%) with abnormal toxicology results were ultimately discharged from the practice. Forty-eight patients (24\%) were on methadone for pain management or on a methadone maintenance treatment program (MMTP). Of patients already on an MMTP, 60\% (29/48) had abnormal urine toxicology results; 3 of these 29 patients were discharged from the practice. Treatment recommendations and outcomes were as follows: continuation of current treatment (41\%), detoxification/ rehabilitation $(13 \%)$, discharge $(6 \%)$, methadone $(8 \%)$, none (2\%), non-opioids for pain (20\%), opioids $(2 \%)$, psychiatric treatment (5\%), and refused detoxification/rehabilitation (20\%) (Figure 2). Within this group, many patients were recommended for one, two, or three treatment types (n1=168; n2=30; n3=4).

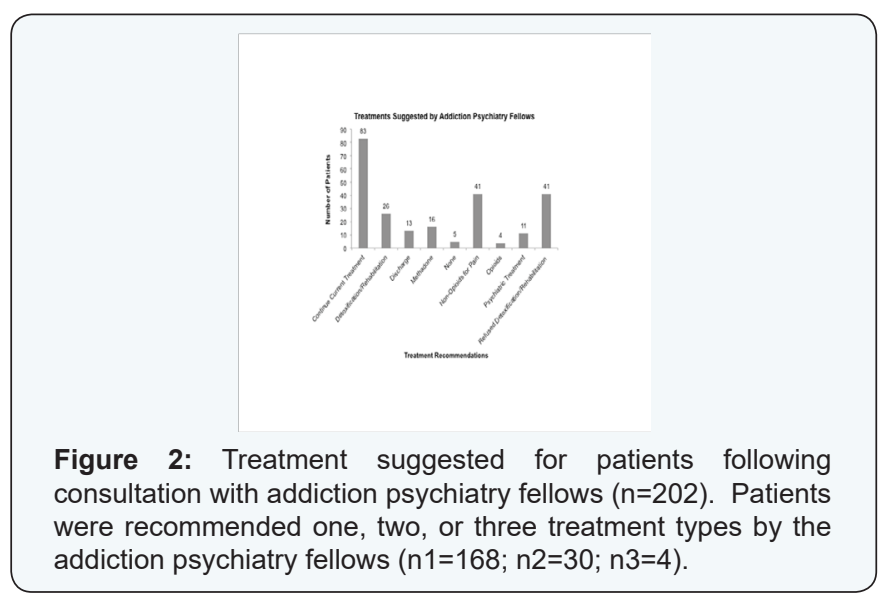

\section{Discussion}

Assessment of risk when prescribing opioids in pain clinics is important. Studies show that $1 \%$ to $85 \%$ of patients depicts some form of ADRB leading to the current recommendations of risk reassessment at every visit $[7,8]$. While several structured opioid refill clinics have been implemented and report mitigation of harm, these findings may not be generalizable. Refill clinics currently proposed may require additional resources for set-up, limiting their feasibility in the usual clinical settings $[6,16,17]$. Academic 
centers with training programs in both pain management and addiction psychiatry may provide a unique opportunity for the assessment of patients at higher risk for opioid prescribing. We are reporting the results of a pilot study at an academic medical center where attending physicians, nurse practitioners, and pain fellows could refer their patients for an assessment of opioid prescribing risk. Addiction psychiatry fellows, proctored by the chief of the pain division and the director of the addiction psychiatry fellowship, performed opioid-prescribing risk assessments. Pain fellows and nurse practitioners made most of the referrals suggesting that less experienced practitioners were less confident determining risk; however, these practitioners seemed to be able to predict ADRB, suggested by positive toxicology testing in $63 \%$ $(128 / 202)$ of their referrals.

The reported pain diagnoses were mirrored those reported in other in pain clinics with most consultations related to low back pain. Twenty four percent of the patients referred for assessment were on a methadone maintenance treatment program. As demonstrated byurine toxicology abnormalities in $60 \%$ of patients, psychiatric evaluation was still necessary despite this alternative drug abuse prevention attempt. Moreover, only $35 \%$ of the cases referred to addiction psychiatry fellows were recommended for continuation of current opioid therapy. Through consultation with addiction psychiatry fellows, a majority of referrals were identified as high risk for opioid abuse. The fellows rated this rotation high and indicated that it was very "highly valuable" in their training. Because a significant proportion of patients seen in the pain clinic also have comorbid psychiatric diagnoses, building a culture of cross-disciplinary approaches provides a more robust approach in managing these difficult patients [18].

\section{References}

1. Hale ME, Zimmerman TR, Ma Y, Malamut R (2016) Evaluation of Quality of Life, Functioning, Disability, and Work/School Productivity Following Treatment with an Extended-Release Hydrocodone Tablet Formulated with Abuse-Deterrence Technology: A 12-month Openlabel Study in Patients with Chronic Pain. Pain Pract.

2. Khanna IK, Pillarisetti S (2015) Buprenorphine - an attractive opioid with underutilized potential in treatment of chronic pain. J Pain Res 8: 859-870

3. Lazzari M, Greco MT, Marcassa C, Finocchi S, Caldarulo C, et al. (2015) Efficacy and tolerability of oral oxycodone and oxycodone/naloxone combination in opioid-naïve cancer patients: a propensity analysis. Drug Des Devel Ther 9: 5863-5872.

4. Bohnert AS, Valenstein M, Bair MJ, Ganoczy D, McCarthy JF, et al. (2011) Association between opioid prescribing patterns and opioid overdoserelated deaths. JAMA 305(13): 1315-1321.
5. Merlin JS, Turan JM, Herbey I, Westfall AO, Starrels JL, et al. (2014) Aberrant drug-related behaviors: a qualitative analysis of medical record documentation in patients referred to an HIV/chronic pain clinic. Pain Med 15(10): 1724-1733.

6. Hao J, Lucido D, Cruciani RA (2014) Potential impact of abrupt opioid therapy discontinuation in the management of chronic pain: a pilot study on patient perspective. J Opioid Manag 10(1): 9-20.

7. Brown J, Setnik B, Lee K, Wase L, Roland CL, et al. (2011) Assessment, stratification, and monitoring of the risk for prescription opioid misuse and abuse in the primary care setting. J Opioid Manag 7(6): 467-483.

8. Meltzer EC, Rybin D, Meshesha LZ, Saitz R, Samet JH, et al. (2012) Aberrant drug-related behaviors: unsystematic documentation does not identify prescription drug use disorder. Pain Med 13(11): 14361443.

9. Fishbain DA, Cole B, Lewis J, Rosomoff HL, Rosomoff RS (2008) What percentage of chronic nonmalignant pain patients exposed to chronic opioid analgesic therapy develop abuse/addiction and/or aberrant drug-related behaviors? A structured evidence-based review. Pain Med 9(4): 444-459.

10. Vijayaraghavan M, Penko J, Guzman D, Miaskowski C, Kushel MB (2012) Primary care providers' views on chronic pain management among high-risk patients in safety net settings. Pain Med 13(9): 1141-1148.

11. Vijayaraghavan M, Penko J, Bangsberg DR, Miaskowski C, Kushel MB (2013) Opioid analgesic misuse in a community-based cohort of HIVinfected indigent adults. JAMA Intern Med 173(3): 235-237.

12. Larance B, Bruno R, Lintzeris N, Degenhardt L, Black E, et al. (2016) Development of a brief tool for monitoring aberrant behaviours among patients receiving long-term opioid therapy: The Opioid-Related Behaviours In Treatment (ORBIT) scale. Drug Alcohol Depend 159: $42-52$.

13. Jamison RN, Martel MO, Huang CC, Jurcik D, Edwards RR (2015) Efficacy of the Opioid Compliance Checklist to Monitor Chronic Pain Patients Receiving Opioid Therapy in Primary Care. J Pain 17(4): 414423.

14. Butler SF, Budman SH, Fernandez KC, Houle B, Benoit C, et al. (2007) Development and validation of the Current Opioid Misuse Measure. Pain 130(1-2): 144-156.

15. Compton PA, Wu SM, Schieffer B, Pham Q Naliboff BD (2008) Introduction of a self-report version of the Prescription Drug Use Questionnaire and relationship to medication agreement noncompliance. J Pain Symptom Manage 36(4): 383-395.

16. Wiedemer NL, Harden PS, Arndt IO, Gallagher RM (2007) The opioid renewal clinic: a primary care, managed approach to opioid therapy in chronic pain patients at risk for substance abuse. Pain Med 8(7): 573-584.

17. Meghani SH, Wiedemer NL, Becker WC, Gracely EJ, Gallagher RM (2009) Predictors of resolution of aberrant drug behavior in chronic pain patients treated in a structured opioid risk management program. Pain Med 10(5): 858-865.

18. Crofford LJ (2015) Psychological aspects of chronic musculoskeletal pain. Best Pract Res Clin Rheumatol 29(1): 147-155. 
Your next submission with JuniperPublishers will reach you the below assets

- Quality Editorial service

- Swift Peer Review

- Reprints availability

- E-prints Service

- Manuscript Podcast for convenient understanding

- Global attainment for your research

- Manuscript accessibility in different formats (Pdf, E-pub, Full Text, Audio)

- Unceasing customer service

Track the below URL for one-step submission http://juniperpublishers.com/online-submission.php 